\title{
The Effects of the late 2000s Global Financial Crisis on Australia's Construction Demand
}

Heng Jiang, (Deakin University, Geelong, Australia)

Xiao-Hua Jin, (University of Western Sydney, Australia)

Chunlu Liu, (Deakin University, Australia)

\begin{abstract}
An accurate measurement of the impacts of external shocks on construction demand will enable construction industry policymakers and developers to make allowances for future occurrences and advance the construction industry in a sustainable manner. This paper aims to measure the dynamic effects of the late 2000s global financial crisis on the level of demand in the Australian construction industry. The vector error correction (VEC) model with intervention indicators is employed to estimate the external impact from the crisis on a macro-level construction economic indicator, namely construction demand. The methodology comprises six main stages to produce appropriate VEC models that describe the characteristics of the underlying process. Research findings suggest that overall residential and non-residential construction demand were affected significantly by the recent crisis and seasonality. Non-residential construction demand was disrupted more than residential construction demand at the crisis onset. The residential construction industry is more reactive and is able to recover faster following the crisis in comparison with the nonresidential industry. The VEC model with intervention indicators developed in this study can be used as an experiment for an advanced econometric method. This can be used to analyse the effects of special events and factors not only on construction but also on other industries.
\end{abstract}

Keywords: Vector error correction, Intervention analysis, Construction demand, The global financial crisis

\section{Introduction}

The construction industry is an important sector of a nation's economy. It makes a significant contribution to the economic output and provides employment and business opportunities ( $\mathrm{Li}$ \& Liu 2012). Ofori (1990) highlighted that construction is the engine of economic growth. However, the construction industry is greatly affected by the performance of the economy as the output of construction is a response to the demand for buildings, a derived demand for other sectors (Song \& Liu 2006). The relationship between economic and construction cycles is widely discussed by many construction economists. A close relationship was found between the construction cycle and the economic cycle in Singapore, where the short-term business cycle has a direct influence on the demand for construction (Hua 1998). This close relationship implies that shocks from specific external events, such as global financial crises, affect not only the general economy but also the construction industry. During periods of economic austerity, the level of demand in the construction industry will be affected dramatically due to reduction of construction spending by public and private sectors (Hua 2005). With this as the backdrop, construction economists apply an advanced and accurate method to assess the impacts of such external shocks on the construction industry and its lagged effects.

Limited research has been undertaken to assess the effect of external shocks on the construction industry. For example, Hua (2005) estimated the dynamic effects of the 1997 Asian financial crisis on the demand for construction in Singapore using the auto-regressiveintegrated moving average (ARIMA) model. Hua (2005) reported different net effects of the Asian financial crisis on the demand from both the public and private sectors, with a positive 
response in the public sector and a negative response in the private sector. A study by Fan et al. (2010), based on the ARIMA technique, discussed the effects of the SARS outbreak and the Asian financial crisis on the construction industry in Hong Kong. The study concluded that the total demand for construction was only slightly impacted by the SARS outbreak and financial crisis, but the financial crisis deeply influenced demand in the residential sector.

The global financial crisis of 2007-2009 is considered the worst financial crisis since the Great Depression of the 1930s (Jiang \& Liu 2011, Murphy 2011). In July 2007, US investors lost confidence in the value of sub-prime mortgages, resulting in a liquidity shortfall in the United States banking system. This was followed by the collapse of large financial institutions and downturns in stock markets around the world. The crisis began in 2007, but fully impacted the global economy in 2008 and 2009. The annual GDP growth rates from 2007 to 2009 respectively were 3.8\%, 1.6\% and $-2.2 \%$ for the world economy (Nayyar 2011). The International Labour Organisation claimed that worldwide unemployment rose by at least 30 million people, and reached as high as 50 million people during 2007 and 2009 (Blankenburg \& Palma 2009). The collapse of Lehman Brothers on September 14, 2008 marked the beginning of a new phase in the global financial crisis (Berkmen et al. 2009). In the following month, the financial crisis spread from the US to Europe and worldwide. The Australian economy was injured deeply in the crisis. In the period between 2007 and mid2008, the Australian economy registered a high growth rate at around 4\% (ABS 2012). However, in December 2008, the Australian stock market experienced the largest fall on record, with AUD 3.4 billion, while the Australian unemployment rate increased by $2 \%$ during the 2008 and 2009 global economic downturn. At the same time, the global financial crisis also triggered unexpected shock waves in the Australian construction industry. In Australia the value of construction approvals shrunk by almost a quarter in March 2009, compared to its peak in March 2008, while house prices declined 6\% from March 2008 to March 2009.

The effects of the recent financial crisis on the construction industry can be readily observed. Hence, an analysis of the effects of the crisis on growth in the construction industry can help to facilitate resource planning. This, in turn, ensures all valuable public resources can be allocated for the construction sectors, to retain labour and skills after this global recession. In previous studies, the ARIMA model was the main technique used to assess external shocks of specific events on the construction industry. This technique assesses the impacts of external shocks on the construction industry, based solely on past data of the time series. A significant issue for this measuring method is that it ignores the impacts of changes in economic conditions on the variation in construction economic indicators. Furthermore, previous research on event analysis focuses on how events affect the market or concerned indicators but doesn't assess the market or indicators in the absence of an event. This study addresses this issue by estimating construction demand based on two scenarios: A - the change of construction demand is assumed to follow the trend of economic growth in the pre-crisis period, with no effects of the global financial crisis, and B - the change in construction demand is assumed to follow the trend of economic growth in the post-crisis era. An advanced econometrics method, vector error correction (VEC) model with intervention indicators, would serve as a more appropriate modelling technique for assessing the effects of external shocks and impacts of changes of local economic conditions on construction demand. Indeed, an accurate measurement of the impacts of external shocks on construction demand will enable construction industry policymakers and developers to make allowances for future similar occurrences and develop the construction industry in a sustainable manner.

In this study the main stages for assessing the effects of global financial crises on the construction demand are: firstly, create two intervention indicators to represent the duration of the event and seasonal effect; secondly, develop VEC models with intervention indicators for the construction demand; then, estimate endogenous variables and intervention 
indicators in the robust VEC model; next, identify whether the global financial crisis and seasonality affect the construction demand or not with Australian Bureau of Statistics (ABS) data; subsequently solve the robust VEC model during the intervention period and estimate the intervention of special events (i.e. the global financial crisis and seasonality); and finally interpret the estimated results and the intervention effects of the event on the construction demand.

\section{VEC Model Development}

\section{Intervention Indicators}

Intervention analysis has been applied in many studies for example in assessing the intervention of institution controls on the rate of change in the US consumer price index (Box \& Tiao 1975), analysing the dynamic effects of the 1997 Asian financial crisis on construction demand and tender price in Singapore (Hua 2005), and measuring the impact of the Sydney Olympic Games in 2000 and the Bali Bombing in 2005 on the tourism industry in Australia (Yap \& Allen 2011). The characteristics of intervention analysis technique have been explored in other studies, such as Box and Tiao (1975), and Hua (2005). In brief, the intervention indicators can be represented in two forms; namely a step and a pulse. As exogenous variables the indicator variables take the value 0 and 1 to denote non-occurrence and occurrence of the intervention. If the intervention function is a step, then the value of the indicator is 0 until the event begins at time $T$. At the occurrence of the event, the intervention equals 1 and the indicator can be denoted by $S_{t}^{T}$ where:

$$
S_{t}^{T}= \begin{cases}0, & t<T \\ 1, & t \geq T\end{cases}
$$

If the intervention function is a pulse function, then the value of the indicator is 0 at nonoccurrence of the event. At the occurrence of the event, the indicator is 1 and it remains 1 for the duration of the occurrence of the event. In some cases, a conventional pulse is only one time period, or the duration of the event. A indicator for pulse function can be denoted by $P_{t}^{T}$ where:

$$
P_{t}^{T}= \begin{cases}0, & t \neq T \\ 1, & t=T\end{cases}
$$

The step and conventional pulse functions are represented by input variables and these two functions are interrelated. In this study, the intervention indicator of the effects of the late 2000s global financial crisis is represented as an extended pulse function, and seasonal impact is represented as a conventional pulse function. The first sign of deterioration in Australia's construction industry was in the second half of 2008, when the demand for construction declined more than 29\%. At the same time, the first significant policy response to the global financial crisis came from the Australian Commonwealth Government. The government announced it would guarantee all bank deposits, and an economic stimulus package worth AUD 10.4 billion was announced. In this package, AUD 1.5 billion was allocated to support housing construction. This announcement could be considered an ideal indicator in denoting when the financial crisis began to affect the Australian economy. Through a series of effective boost strategies, the approvals of Australian construction industry reached the same level in the September quarter of 2009 as at the beginning of the global financial crisis. However the approved value of construction work registered a dramatic decline (26\%) from the December quarter of 2009 to the June quarter of 2010, and was mainly due to the sharp decline in the value of non-residential construction approvals. This can be signalled as the lagged effects of the late 2000s global financial crisis. Following this, the demand in the Australian construction industry remained at a low level but grew slightly after the June quarter of 2010 to the March quarter, 2012. This signalled an end to the lagged effects of the crisis. Indeed, the intervention period of the late 2000s global financial crisis on the Australian construction industry can be defined as starting in the September quarter, 2008 and ending in the June quarter, 2010. 


\section{The Vector Error Correction Model with Intervention Indicators}

The vector error correction model is a combination of the vector autoregressive model and co-integration restrictions. Co-integration, an econometric property of time series variables, is generally used to estimate the long-run relationships between non-stationary variables. If the level of time series data is not stationary, but a linear combination of variables is stationary after the first difference, then the series are co-integrated to an order one or $I(1)$. They will tend to return to this trend in the long term, even though they deviate from each other in the short term. A prior condition for the co-integration test is that all the variables should be integrated to the same order or contain a deterministic trend (Engle \& Granger 1991; Liu et al. 2009). A unit root test is conducted for each variable using the Augmented Dickey-Fuller (ADF) unit root test and the Phillips-Perron (PP) unit root test, which were introduced by Dickey and Fuller (1987), and Phillips and Perron (1988) respectively.

The general VEC model employed by Jiang and Liu (2011) is represented in Equation (3).

$$
\Delta Y_{t}=C+\Pi Y_{t-1}+\sum_{i=1}^{k-1} \Gamma_{i} \Delta Y_{t-i}+\varepsilon_{t}
$$

where $Y_{t}$ is an independent $I(1)$ variable being integrated to an $I(0)$ vector, $\mathrm{C}$ is the intercept, $\Gamma$ is the matrix reflecting the short-run dynamic relationship among elements of $Y_{t}$, and $\varepsilon_{t}$ is residual. $\Delta=(I-L), L$ is the lag operator, $k$ is the number of lags, where $\Pi$ is the matrix containing long-run equilibrium information. If the elements of $Y_{t}$ are $I(1)$ variables and cointegrated with rank $(\Pi)=r<p$, then the rank of $\Pi$ can be rewritten as $\Pi=\alpha \beta^{\prime}=\alpha e c m_{t-1}$, $e c m_{t-1}$ is the error correction term and $\beta^{\prime} Y_{t}$ is stationary. This implies that there exist $r<p$ stationary linear combinations of $Y_{t} . \beta$ is a vector of co-integration relationships and $\alpha$ is a loading matrix defining the adjustment speed of the variables in $Y$ to the long-run equilibrium defined by the co-integrating relationships.

Johansen co-integration test was introduced by Johansen and Juselius (1990) to conduct the multivariate maximum likelihood approach and revealed the number or co-integration equations without using arbitrary normalisation rules. There are five models in the Johansen co-integration test. Model one represents all series as having zero mean. Model two represents deterministic data with an intercept but no trend in the co-integration equations (CE). Model three suggests that data has a linear trend with an intercept but no trend in the CE. Model four has a linear trend with both an intercept and a trend in the CE, while model five suggests a quadratic data trend with an intercept and a trend in the CE. This paper analyses three different specifications in the Johansen co-integration estimation, excluding models 1 and 5, as they are not applicable in real life situations (Hui \& Yue 2006). Lag length of the VEC model is selected for the time series in VAR modelling on the basis of a sequential modified likelihood ratio test statistic, final prediction error, Akaike information criterion, Schwarz information criterion and Hannan-Quinn information criterion. The test results of lag length selection are then input into the Johansen co-integration test for constructing VEC models with different combinations of construction demand and each economic indicator. Once all variables proved to be stationary and co-integrated, a VEC model was formulated.

The VEC model, containing intervention indicators, was earlier used by Ramey (1993) to analyse the effects of seasonality and monetary-policy disturbance on the money market. As an exogenous variable, the intervention indicator has been included in the VEC model to estimate the impacts of the 1985 United Airlines strike and the 1991 Persian Gulf War on the tourism demand and supply for Hawaii (Bonham et al. 2009). Based on the Equation (1), the VEC model with intervention indicators can be represented in Equation (4). 


$$
\Delta Y_{t}=C+\Pi Y_{t-1}+\sum_{i=1}^{k-1} \Gamma_{i} \Delta Y_{t-i}+\sum_{j=1}^{n} \Theta_{N} D_{j, t}+\varepsilon_{t}
$$

Where $D_{j, t}$ is the intervention indicator $j$ at time $t, N$ is the number of endogenous variables, $n$ is the number of exogenous variables, $\Theta_{k}$ are $n \times N$ vectors.

\section{Estimating the VEC Model for Australian Construction Demand Economic Indicators affecting Construction Demand}

The value of construction work approved, or the value of construction approvals, has been used to represent the demand in the construction industry, as it is an indicator of changes in the level of construction demand (Ofori 1990). In this study, the value of construction work approved was selected to represent the demand in construction. This can be defined as the total monetary cost of the construction work that clients are able, and will be able, to purchase in a given period. Furthermore, the total residential and non-residential values of construction work approved were abstracted from the Australian Bureau of Statistics for assessing the effects of the recent global financial crisis on the different types of construction industries (ABS 2012). The time series of different types of construction demand are shown in Figure 1. It indicates that all types of construction demand in the Australian construction industry had a significant decline in 2008 Q3, followed by a large fluctuation to 2010 Q2. It then remained constant between 2010 Q2 and 2012 Q3.

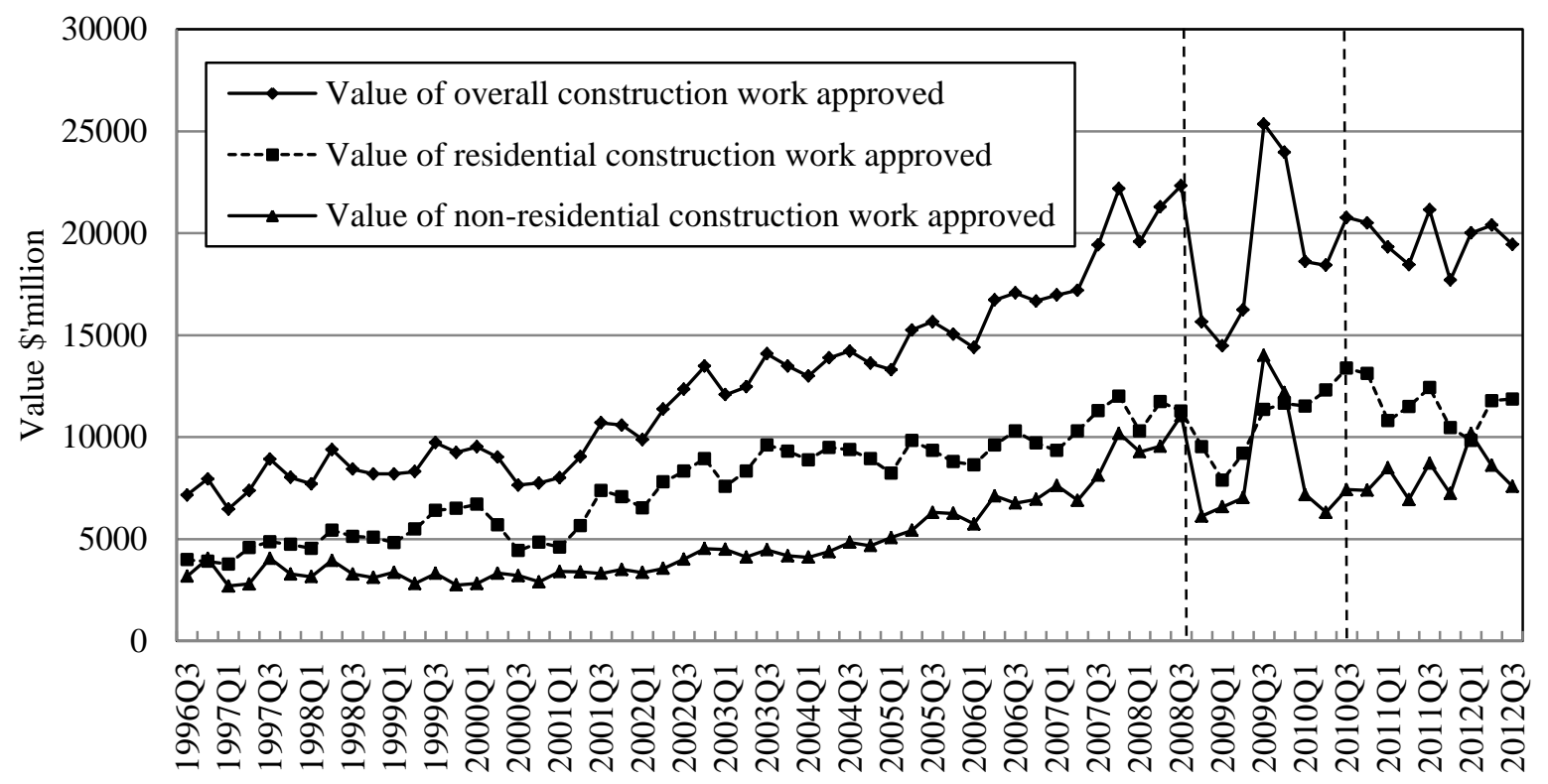

Figure 1 A plot of the time series for three types of the value of construction work approved (two vertical dot lines highlight the duration of the effect of the late 2000 s financial crisis on the construction industry)

Economic indicators including construction price, national income, householder expenditure, size of population, unemployment rate, interest rate and the value of export have been widely used to model construction demand. A construction producer price reflects the movement of prices in the construction industry for each period of time (Hua 1998). Ball et al (2000) suggested that for each market sector, construction prices should be determined by the total demand. Construction prices differ by region, partly as a result of local resources and demand, because a fluctuating demand will lead to fluctuating prices and vice versa (Meikle 2001). Akintoye and Skitmore (1994) adopted construction price as one of the 
significant factors for modelling housing construction demand in the private sector. Any variation in the national income will affect the level of demand for construction and the construction price in both the residential and non-residential industries. Consumer demand in goods and services will soar in a period of economic prosperity, which will also trigger an increase in the level of demand for construction space (Akintoye \& Skitmore 1994). The change in household expenditure demonstrates the expectation of householders with regard to the future national economy. Increasing the expenditure of householders will lessen the resources available to the construction industry, which will indirectly affect the level of demand for construction. Demographic influences have been widely cited for modelling construction economic indicators, such as demand and prices. The growth of a population raises the basic need for new dwellings and has been identified as a key determinant of the demand for residential construction (Tang et al. 1990; Hua 1998; Fan et al. 2010). The unemployment rate is measured as the total number of people not in employment who are ready and able to work (Hua 1998). An increase in unemployment may discourage investment in the construction industry, because employment is the main source of income for residents and a rise in unemployment rate represents a lowering of the purchasing power of the population. Furthermore, Ma and Liu (2013) applied demographical structure and housing market scales to develop a demographical distance for investigating the house price convergences in Australian capital cities. Fan et al. (2010) indicated that a change in interest rates can affect the lending costs of clients, contractors, developers and company profits. A lower interest rate will encourage investments in the construction industry and thus raise the level of demand for construction. In contrast, an increase in interest rates will raise the cost of bank lending for construction projects and lead to a decline in purchasing power. It can be seen that the average export of goods and services in Australia is more than $20 \%$ of the total GDP (ABS 2012). This means that the export industry is a vital sector, not only for the national economy, but also for other sectors.

The quarterly data series of selected economic indicators and the demand for construction were abstracted from the ABS in the period of September 1996 to September 2012. The data series from September 2008 to June 2010 were used to undertake an intervention analysis to analyse the impact of the recent global financial crisis on the construction demand in Australia. All the time series data used in this study has been expressed as natural logarithm variables. In collecting the variables for estimation, the following important issues were taken into account (Akintoye et al. 1998); economic plausibility of their leading character; availability of the time series with as few interruptions as possible; and availability of the data with minimum delay.

\section{The Estimates of VEC Models with Intervention Indicators}

The VEC model with the late 2000s financial crisis intervention $\left(D_{1, t}\right)$ and seasonal intervention $\left(D_{2, t}\right)$ for different types of construction demand $\left(C D_{t}^{q}\right)$ can be constructed in Equation (5).

$$
\begin{aligned}
\Delta C D_{t}^{q}=C+\alpha & \left(e c m_{t-1} Y_{\mathrm{t}-1}+\rho_{0}\right)+\sum_{i=1}^{k} \theta_{1, i} \Delta C D_{t-1}^{q}+\sum_{i=1}^{k} \theta_{2, i} \Delta C P I_{t-i}+\sum_{i=1}^{k} \theta_{3, i} \Delta N I_{t-i} \\
& +\sum_{i=1}^{k} \theta_{4, i} \Delta H H E_{t-i}+\sum_{i=1}^{k} \theta_{5, i} \Delta U R_{t-i}+\sum_{i=1}^{k} \theta_{6, i} \Delta P O P_{t-i}+\sum_{i=1}^{k} \theta_{7, i} \Delta I R_{t-i} \\
& +\sum_{i=1}^{k} \theta_{8, i} \Delta V O E_{t-i}+\delta D_{1, t}+\varphi D_{2, t}+\varepsilon_{t}
\end{aligned}
$$

Where $\alpha$ is the adjustment coefficient, $\rho_{0}$ is the intercept of co-integrating equations. $\theta_{j, i}$ reflects the short-run aspects of the relationships between the independent variables and the target variable. At time $t, C P I_{t}$ is the construction producer price, $N I_{t}$ is the national income, 
$H H E_{t}$ is the household expenditure, $U R_{t}$ is the unemployment rate, $P O P_{t}$ is the size of population, $I R_{t}$ is the interest rate and $V O E_{t}$ is the value of export. $\delta$ is the coefficient of the late 2000s financial crisis dummy variable, $\varphi$ is the coefficient of the seasonal dummy variable, $D_{1, t}$ and $D_{2, t}$ are the one-off event dummy variables for the financial crisis and seasonal effect respectively.

Before constructing the VEC models, the time series data are first tested for unit root or the order of integration. The ADF and PP unit root tests were carried out to test stationarity for all the variables. The results are summarised in Table 1 and suggest that all the variables were stationary after the first difference at the 0.01 and 0.05 significance levels. Based on the VAR lag length selection system, the smallest values of the LR FPE, AIC, SC and HQ tests indicate that the lag length for the VEC models for overall construction demand, residential and non-residential construction demand all equalled three. Following that, cointegration tests were carried out. The results of the trace statistics indicate that each variable $Y_{t}$ has a linear trend with an intercept, and however three types of construction demand have no trend in the co-integrating relations. The deterministic trend in model three and one co-integration relationship was identified and implemented into these three VEC models. These results suggest that the three types of construction demand and selected economic indicators do not move independently of each other in the long-term and also share some common trends.

\begin{tabular}{|c|c|c|c|c|c|c|c|c|}
\hline \multirow{3}{*}{ Indicators } & \multicolumn{4}{|c|}{ ADF unit root test } & \multicolumn{4}{|c|}{ PP unit root test } \\
\hline & \multicolumn{2}{|c|}{ Level } & \multicolumn{2}{|c|}{ First difference } & \multicolumn{2}{|c|}{ Level } & \multicolumn{2}{|c|}{ First difference } \\
\hline & T-Stat & P-value & T-Stat & P-value & T-Stat & P-value & T-Stat & P-value \\
\hline$C D$ & 2.02 & 0.99 & -8.62 & $0.00^{\star *}$ & -1.25 & 0.65 & -11.95 & $0.00^{* *}$ \\
\hline CPPI & 2.43 & 1.00 & -3.18 & $0.03^{*}$ & -0.26 & 0.92 & -3.18 & $0.03^{*}$ \\
\hline $\mathrm{NI}$ & 0.34 & 0.98 & -4.92 & $0.00^{* *}$ & 0.41 & 0.98 & -6.01 & $0.00^{* *}$ \\
\hline $\mathrm{HHE}$ & -1.73 & 0.41 & -6.35 & $0.00^{* *}$ & -1.74 & 0.41 & -6.27 & $0.00^{\star *}$ \\
\hline UR & -1.12 & 0.24 & -4.11 & $0.01^{*}$ & -1.26 & 0.19 & -4.11 & $0.01^{*}$ \\
\hline POP & 1.97 & 0.99 & -3.68 & $0.03^{*}$ & 1.18 & 1.00 & -7.54 & $0.00^{* *}$ \\
\hline IR & -0.38 & 0.54 & -4.63 & $0.00^{* *}$ & -0.75 & 0.39 & -4.49 & $0.00^{* *}$ \\
\hline VOE & 2.47 & 1.00 & -8.12 & $0.00^{* *}$ & -1.87 & 0.34 & -8.79 & $0.00^{* *}$ \\
\hline $\mathrm{RCD}$ & -1.52 & 0.51 & -7.02 & $0.00^{* *}$ & -1.25 & 0.65 & -11.51 & $0.00^{\star *}$ \\
\hline NRCD & -1.79 & 0.38 & -6.12 & $0.00^{* *}$ & -1.48 & 0.54 & -15.70 & $0.00^{* *}$ \\
\hline
\end{tabular}

Table 1 Summarised results of ADF and PP unit root tests

* denotes rejection of null hypothesis of unit root based on their P-value at the 0.05 significance level.

** denotes rejection of null hypothesis of unit root based on their P-value at the 0.01 significance level.

Having found the long-term relationships between three types of construction demand and selected economic indicators, three VEC models with global event and seasonal intervention indicators were constructed based on Equation (5). The estimates of these three VEC models, with intervention indicators for overall, residential and non-residential construction demand, are reported in Table 2. The estimates of VEC models for overall and nonresidential construction demand show that overall and non-residential construction demand is affected by construction price, national income, householder expenditure, unemployment rate, population, interest rates and the value of export. In contrast, the residential construction demand is not affected by the construction price. In addition, the lagged construction demand, the growth of population and the interest rate have significant roles in explaining the level of demand in the construction industry. 


\begin{tabular}{|c|c|c|c|}
\hline Variables & $\Delta C D_{t}$ & $\triangle R C D_{t}$ & $\triangle N R C D_{t}$ \\
\hline$C D_{t-1}$ & 1 & 1 & 1 \\
\hline$C P P I_{t-1}$ & $-1.394(-2.744)^{* * *}$ & $-0.572(-1.029)$ & $2.843(4.905)^{\star \star \star}$ \\
\hline$N I_{t-1}$ & $-2.283(-5.117)^{* * *}$ & $-4.107(-11.291)^{\star * *}$ & $-5.638(-4.707)^{\star \star \star}$ \\
\hline$H H E_{t-1}$ & $7.307(10.990)^{* \star *}$ & $8.323(6.431)^{* * *}$ & $4.785(3.322)^{\star \star \star}$ \\
\hline$U R_{t-1}$ & $0.734(1.966)^{* *}$ & $1.077(12.523)^{* * *}$ & $0.995(3.001)^{\star \star \star}$ \\
\hline$P O P_{t-1}$ & $-8.421(-5.163)^{\star \star}$ & $7.363(5.790)^{* *}$ & $-7.620(-3.603)^{\star *}$ \\
\hline$I R_{t-1}$ & $0.674(8.665)^{* \star \star}$ & $0.556(1.974)^{\star \star}$ & $-0.837(-5.608)^{\star \star \star}$ \\
\hline$V O E_{t-1}$ & $-0.891(-3.264)^{* * *}$ & $-1.419(-2.726)^{\star \star}$ & $4.973(12.079)^{\star \star \star}$ \\
\hline C & 38.698 & -48.765 & 84.692 \\
\hline CointEq1 $(\alpha)$ & $0.194(0.050)$ & $0.248(-1.743)^{*}$ & $-0.153(-0.196)$ \\
\hline$\rho_{0}$ & $-0.041(-1.259)$ & $-0.106(-0.880)$ & $0.178(0.631)$ \\
\hline D1 & $-0.179(-2.784)^{\star *}$ & $-0.121(-1.641)^{\star}$ & $-0.346(-3.126)^{\star \star *}$ \\
\hline D2 & $-0.109(-2.353)^{* * *}$ & $-0.144(-3.634)^{* * *}$ & $-0.074(-1.686)^{*}$ \\
\hline$R$-squared & 0.859 & 0.816 & 0.828 \\
\hline Sum sq. residue & 0.138 & 0.122 & 0.552 \\
\hline S.E. equation & 0.067 & 0.071 & 0.127 \\
\hline Log likelihood & 88.550 & 83.633 & 53.341 \\
\hline Error correction & $t-1$ & $t-2$ & $t-3$ \\
\hline \multicolumn{4}{|c|}{ Overall construction demand } \\
\hline$\triangle C D$ & $-0.491(-2.941)^{\star * *}$ & $-0.391(-1.999)^{\star \star}$ & $-0.004(-0.032)$ \\
\hline$\triangle C P P I$ & $3.515(1.203)$ & $-1.963(-0.631)$ & $-4.263(-1.516)$ \\
\hline$\Delta N I$ & $-2.200(-1.428)$ & $-1.075(-0.675)$ & $-2.169(-1.382)$ \\
\hline$\triangle H H E$ & $0.641(0.279)$ & $6.679(2.759)$ & $-0.013(-0.005)$ \\
\hline$\Delta U R$ & $0.7526(1.381)$ & $-0.157(-0.321)$ & $-0.217(-0.547)$ \\
\hline$\triangle P O P$ & $13.749(0.689)$ & $39.717(2.164)^{\star *}$ & $-6.155(-0.227)$ \\
\hline$\Delta I R$ & $0.087(0.402)$ & $-0.024(-0.115)$ & $-0.508(-2.626)^{\star \star *}$ \\
\hline$\triangle V O E$ & $0.544(1.112)$ & $-0.379(-0.743)$ & $-0.030(-0.057)$ \\
\hline \multicolumn{4}{|c|}{ Residential construction demand } \\
\hline$\triangle R C D$ & $-0.034(-0.117)$ & $-0.108(-0.063)$ & $0.128(0.932)$ \\
\hline$\triangle C P P I$ & $6.619(2.031)^{\star \star}$ & $-1.393(-0.407)$ & $-3.151(-0.819)$ \\
\hline$\Delta N I$ & $-0.639(-0.381)$ & $-1.335(-0.843)$ & $-2.956(-1.857)^{\star \star}$ \\
\hline$\triangle H H E$ & $2.994(1.325)^{*}$ & $4.765(1.794)^{\star \star}$ & $-1.251(-0.493)$ \\
\hline$\Delta U R$ & 0.408 (0.699) & $-0.749(-1.503)$ & $-0.784(-1.801)$ \\
\hline$\triangle P O P$ & $33.418(1.333)^{*}$ & $32.201(1.430)^{*}$ & $-14.196(-0.471)$ \\
\hline$\Delta I R$ & $0.327(0.942)$ & $0.017(0.057)$ & $-0.118(-0.552)$ \\
\hline$\triangle V O E$ & $0.185(0.369)$ & $-0.548(-1.069)$ & $-0.513(-0.853)$ \\
\hline \multicolumn{4}{|c|}{ Non-residential construction demand } \\
\hline$\triangle N R C D$ & $-0.011(-0.028)$ & $-0.269(-0.820)$ & $-0.065(-0.249)$ \\
\hline$\triangle C P P I$ & $0.333(0.065)$ & $-2.801(-0.502)$ & $1.756(0.357)$ \\
\hline$\Delta N I$ & $-6.660(-2.332)^{\star * *}$ & $-1.054(-0.365)$ & $-2.339(-0.839)$ \\
\hline$\triangle H H E$ & $-2.766(-0.629)$ & $7.278(1.698)^{\star *}$ & $-1.261(-0.279)$ \\
\hline$\Delta U R$ & $2.118(2.344)^{* * *}$ & $0.591(0.669)$ & $0.838(1.056)$ \\
\hline$\triangle P O P$ & $0.561(0.018)$ & $42.610(1.175)^{\star *}$ & $-31.573(-0.649)$ \\
\hline$\Delta I R$ & $0.364(1.117)$ & $0.600(1.623)^{*}$ & $-0.649(-1.842)^{\star *}$ \\
\hline$\triangle V O E$ & $2.054(1.527)^{*}$ & $0.593(0.463)$ & $2.333(2.336)^{* * *}$ \\
\hline
\end{tabular}

Table 2 Estimation results of the VEC models with intervention indicators for three types of construction demand

* denotes t-statistics significant at 0.1 level

** denotes t-statistics significant at 0.05 level

*** denotes t-statistics significant at 0.01 level

Jiang, $\mathrm{H}$ et al (2013) 'The effects of the late 2000s global financial crisis on Australia's construction demand', Australasian Journal of Construction Economics and Building, 13 (3) 65-79 
The estimates of intervention indicators (e.g. the recent global financial crisis and seasonality) in these VEC models indicate whether these external impacts can affect these three types of construction demand in Australia. The estimation results suggest that overall, residential and non-residential construction demand have received significant negative impacts from both the late 2000s global financial crisis and seasonality. The VEC models for three types of construction demand were examined for their model fit based on values of Rsquared, Sum square residue, S.E. equation and Log likelihood. These values suggest that the VEC models are stable and well-fitted. The R-square values in three VEC models indicate that above $81 \%$ of the variations in Australian construction demand could be captured by these models, and the results of model fit also suggest that the estimation for the overall construction demand is more accurate compared with the residential and nonresidential construction demand.

\section{Effects of the late 2000s Global Financial Crisis}

The interventions of the recent global financial crisis on the overall, residential and nonresidential construction demand were identified. The VEC models were solved with intervention indicators for the overall, residential and non-residential construction demand during the period of global financial crisis based on the pre-estimated coefficients of independent variables in Table 2. Through this procedure, the values of three types of construction demand with intervention analysis are estimated under two scenarios, each with different assumptions regarding the trend of the social and economic factors selected in estimating construction demand.

\section{Scenario A}

The change of construction demand is assumed to follow the trend of economic growth in the pre-crisis period. The VEC models of three types of construction demand are solved based on the dynamic solution technique, which solves the models according to the forecast series of selected macroeconomic variables during the event period. The solved results and actual values of three types of construction demand are shown in Figure 2.

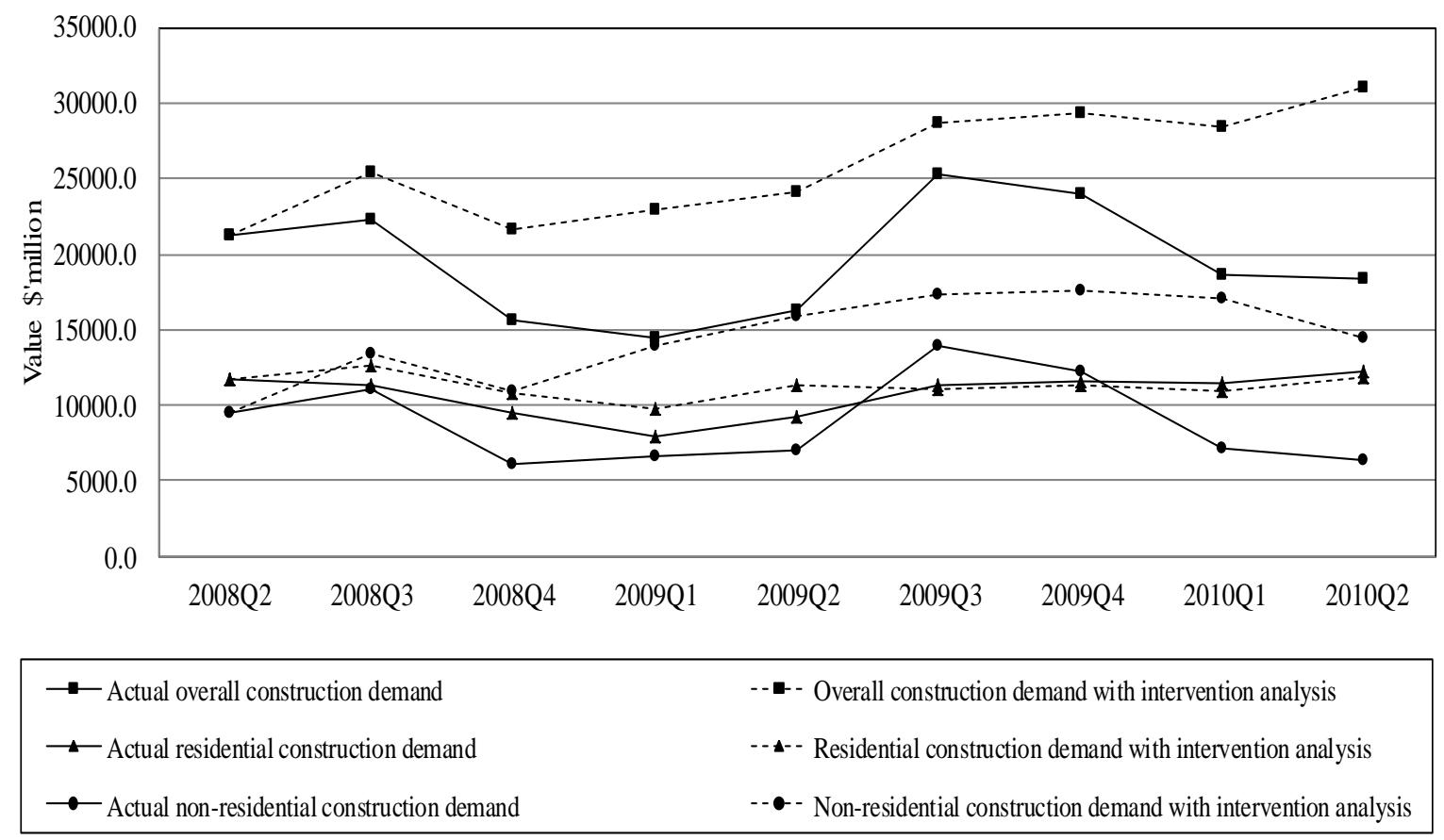

Figure 2 Comparison of different types of actual construction demand and construction demand with intervention analysis during the crisis (Scenario A)

The value of overall, residential and non-residential construction demand with intervention analysis are interpreted as the value of three types of construction demand changes from 
2008Q3 to 2010Q2 without being shocked from the late 2000s global financial crisis. The gaps between values with intervention analysis and actual values can be seen as the net effects of the recent global financial tsunami on the level of demand for construction. The quarterly responses to the onset of the late 2000s global financial crisis, in terms of the change in the construction demand, are different in residential and non-residential industries. The non-residential construction industry was shocked deeper than the residential construction industry, showing a larger gap in the comparison.

The results of the impact of the late 2000s global financial crisis on the overall, residential and non-residential construction demand under Scenario A are summarised in Table 3 . The total net effect of the current crisis on the residential construction demand was AUD -4971 million during 2008Q3 and 2010Q2, while the net effect of the crisis on the non-residential construction demand was AUD -50198.3 million. It should be noted that residential construction demand was positively impacted by the crisis between 2009Q4 and 2010Q2. This positive impact may be due to the series of effective stimulation strategies approved by the Australian Government, which resulted in a high demand in residential construction industry.

\section{Scenario B}

The change in construction demand is assumed to follow the trend of economic growth in the post-crisis era. A statistic solution technique is conducted to solve the value of overall, residential and non-residential construction demand, with intervention analysis based on the statistic data of selected macroeconomic variables. The results are compared with the actual value of construction demand in Figure 3. The comparison results also suggest that the impacts of the global financial crisis on the construction demand are different in the residential and non-residential industries. The non-residential construction industry is found to have been more negatively impacted than the residential construction industry during the crisis.

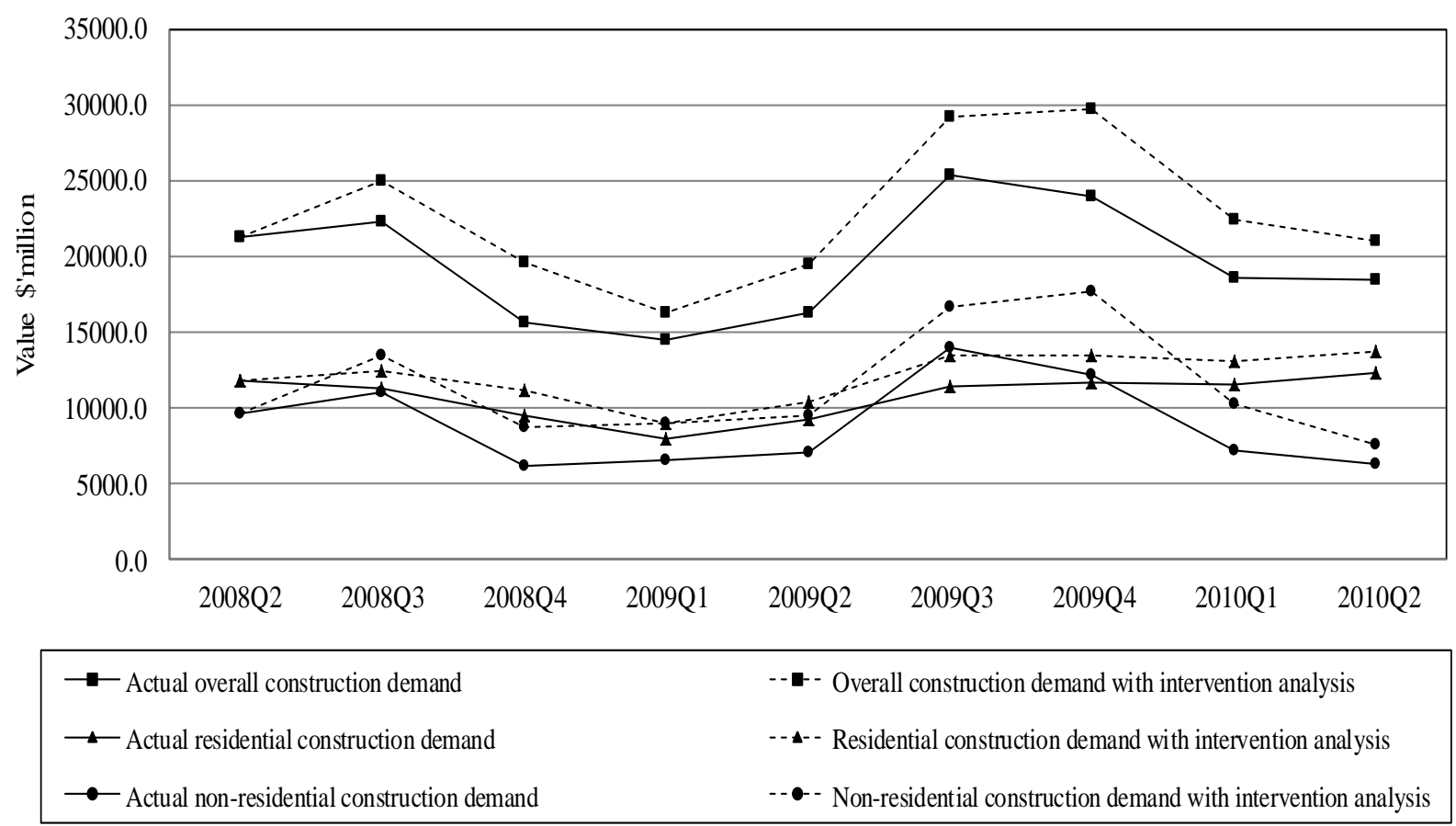

Figure 3 Comparison of different types of actual construction demand and construction demand with intervention analysis during the crisis (Scenario B) 


\begin{tabular}{|c|c|c|c|c|c|c|c|c|c|}
\hline \multirow[t]{2}{*}{ Period } & \multicolumn{3}{|c|}{ Overall construction demand } & \multicolumn{3}{|c|}{ Residential construction demand } & \multicolumn{3}{|c|}{ Non-residential construction demand } \\
\hline & Actual & With analysis & Net effects & Actual & With analysis & Net effects & Actual & With analysis & Net effects \\
\hline $2008 Q 3$ & 22333.6 & 25456.2 & -3122.6 & 11281.4 & 12659.2 & -1377.8 & 11052.2 & 13465.0 & -2412.8 \\
\hline $2008 Q 4$ & 15662.0 & 21625.2 & -5963.2 & 9529.8 & 10840.5 & -1310.7 & 6132.2 & 10902.2 & -4770.0 \\
\hline 2009Q1 & 14476.2 & 22961.2 & -8485.0 & 7887.9 & 9720.6 & -1832.7 & 6588.3 & 13975.5 & -7387.2 \\
\hline 2009Q2 & 16241.9 & 24159.4 & -7917.5 & 9213.2 & 11321.2 & -2108.0 & 7028.7 & 15866.9 & -8838.2 \\
\hline 2009Q3 & 25349.7 & 28660.5 & -3310.8 & 11345.6 & 11034.0 & 311.6 & 14004.1 & 17359.5 & -3355.4 \\
\hline 2009Q4 & 23973.9 & 29352.5 & -5378.6 & 11652.3 & 11309.8 & 342.5 & 12190.0 & 17631.0 & -5441.0 \\
\hline 2010Q1 & 18612.9 & 28491.0 & -9878.1 & 11518.2 & 10960.2 & 558.0 & 7177.0 & 17026.6 & -9849.6 \\
\hline 2010Q2 & 18428.6 & 31013.3 & -12585.0 & 12298.9 & 11852.8 & 446.1 & 6312.1 & 14456.2 & -8144.1 \\
\hline \multicolumn{3}{|c|}{ Total Net effects $=$} & -56640.5 & & & -4971.0 & & & -50198.3 \\
\hline
\end{tabular}

Table 3 Results of the impact of the late 2000 s global financial crisis on the construction demand (Scenario A)

Note: the duration of the intervention period is from 2008Q3 to 2010Q2

\begin{tabular}{|l|l|l|l|l|l|l|l|l|l|}
\hline \multicolumn{1}{|c|}{ Period } & \multicolumn{3}{|c|}{ Overall construction demand } & \multicolumn{2}{c|}{ Residential construction demand } & \multicolumn{3}{c|}{ Non-residential construction demand } \\
\hline & \multicolumn{1}{|c|}{ Actual } & With analysis & Net effects & \multicolumn{1}{|c|}{ Actual } & With analysis & Net effects & \multicolumn{1}{|c|}{ Actual } & With analysis & \multicolumn{1}{c|}{ Net effects } \\
\hline 2008Q3 & 22333.6 & 24946.8 & -2613.2 & 11281.4 & 12450.6 & -1169.2 & 11052.2 & 13430.0 & -2377.8 \\
\hline 2008Q4 & 15662.0 & 19604.2 & -3942.2 & 9529.8 & 11130.2 & -1600.4 & 6132.2 & 8758.9 & -2626.7 \\
\hline 2009Q1 & 14476.2 & 16312.5 & -1836.3 & 7887.9 & 8943.3 & -1055.4 & 6588.3 & 9035.1 & -2446.8 \\
\hline 2009Q2 & 16241.9 & 19430.1 & -3188.2 & 9213.2 & 10431.8 & -1218.6 & 7028.7 & 9442.3 & -2413.6 \\
\hline 2009Q3 & 25349.7 & 29201.0 & -3851.3 & 11345.6 & 13499.2 & -2153.6 & 14004.1 & 16652.3 & -2648.2 \\
\hline 2009Q4 & 23973.9 & 29666.7 & -5692.8 & 11652.3 & 13432.0 & -1779.7 & 12190.0 & 17649.8 & -5459.8 \\
\hline 2010Q1 & 18612.9 & 22460.3 & -3847.4 & 11518.2 & 13050.9 & -1532.7 & 7177.0 & 10288.2 & -3111.2 \\
\hline 2010Q2 & 18428.6 & 21020.0 & -2591.4 & 12298.9 & 13764.5 & -1465.6 & 6312.1 & 7621.4 & -1309.3 \\
\hline Total Net effects & & -27562.8 & & & -11975.2 & & & -22393.4 \\
\hline
\end{tabular}

Table 4 Results of the impact of the late 2000 s global financial crisis on the construction demand (Scenario B)

Note: the duration of the intervention period is from 2008Q3 to 2010Q2 
Based on Scenario B, the results of the impact of the late 2000s global financial crisis on the overall, residential and non-residential construction demand are summarized in Table 4. By comparing the net effect it can be seen that there is a significant decrease of AUD -22393.4 million in the value of demand for the non-residential construction industry, and a total negative effect with AUD -11975.2 million in the residential construction demand caused by the crisis. It is found that in 2009Q3, the residential construction industry received the greatest shock from the financial tsunami which caused a higher loss, with AUD -2153.6 million in the level of demand than other quarters. However, the level of demand in the nonresidential construction industry was impacted the most, with AUD -5459.8 million by the crisis in 2009Q4. In regard to the results of the intervention analysis in Scenario B, the government policy makers should note that the actual value of residential and nonresidential construction demand were AUD 1465.6 million and AUD 1309.3 million less than the estimated values in 2010Q2 respectively. In the latter quarter, a further boost strategy would be to increase investments on construction by these amounts to correct the effects of the late 2000s financial crisis on both the residential and non-residential industries.

Key economy stimulus policies, issued by the Australian government to boost the national economy from global economic downturn, are summarized in Table 5. This table indicates that a fund of nearly AUD 50 billion was announced, being allocated to the non-residential construction industry from 2008Q4 to 2009Q1; the First Home Owner Home Grant (established by the Australian government to encourage and assist residents to buy their first home) was tripled; and interest rates were cut from $7 \%$ to $3 \%$ within three quarters. These stimulation strategies have boosted both the national economy and the construction industry effectively. However, these strategies only stimulated investments in the construction industry in the short term, while approvals in the Australian construction industry reached the same level in the 2009Q3 as at the beginning of the global financial crisis. After that, the lagged effect of the crisis was enhanced, as no further boost strategies were applied by the Government from 2009Q2 to 2010Q2 and interest rates began to increase from October 2009. ABS (2012) reported a dramatic decline of greater than $25 \%$ in the value of construction work approved from 2009Q4 to 2010Q1. Furthermore, the results of Scenarios $A$ and $B$ indicate that the negative effects of the crisis on construction demand changed from strong to weak from 2008Q3 to 2009Q3, then reverted to strong during 2009Q4 and 2010Q2. This fluctuation in the loss of the value of demand may be largely due to the changes in Australian government policies in response to the financial crisis. The actual residential construction demand moves more closely with residential construction demand with intervention analysis when comparing the gaps between actual non-residential construction demand and its estimated value. This suggests that the residential construction industry reacts faster than the non-residential construction industry when facing a special global event.

\section{Conclusions}

Intervention analysis has become an effective technique of event estimation. The estimates of the effect of an event are based on the entire historical data of the variable concerned, and not simply on the comparison of a few quarters. Previous applications, of the intervention analysis in the construction industry, did not fully consider the dynamic relationships between the variable concerned and economic indicators. There were also problems with choosing an appropriate strategy to estimate the effect of the event. Furthermore, while previous research on intervention analysis discussed how the event affects the market or variables concerned, it did not consider the effect should the event not occur. The VEC model, with intervention indicators, was introduced to estimate the impact of the late 2000s global financial crisis on the construction demand in Australia. The dynamic relationships between construction demand and macroeconomic indicators were integrated into the estimation models. The estimation was conducted based on two scenarios, including that the change in construction demand is assumed to follow the trend of economic growth in

Jiang, $\mathrm{H}$ et al (2013) 'The effects of the late 2000s global financial crisis on Australia's construction demand', Australasian Journal of Construction Economics and Building, 13 (3) 65-79 


\begin{tabular}{|c|c|}
\hline Dates of Announcements & Australia's responses to the global financial crisis \\
\hline September 2008 & The RBA announced plans to lower the cash rate by 25 basis points to 7 per cent. \\
\hline October 2008 & The RBA announced plans to lower the cash rate by 100 basis points to 6 per cent. \\
\hline October 2008 & $\begin{array}{l}\text { The Australian government announced plans to guarantee all bank deposits and an economic stimulus package worth AUD } \\
10.4 \text { billion was announced. In this package, AUD } 1.5 \text { billion was allocated to support housing construction. }\end{array}$ \\
\hline November 2008 & The RBA announced plans to lower the cash rate by 75 basis points to 5.25 per cent. \\
\hline December 2008 & $\begin{array}{l}\text { The Australian government announced that the First Home Buyer's grant doubled to AUD } 14,000 \text { for existing homes, and } \\
\text { tripled to AUD } 21,000 \text { for new homes. A fund worth AUD } 4.7 \text { billion was allocated in commencement of large-scale } \\
\text { infrastructure projects. }\end{array}$ \\
\hline December 2008 & The RBA announced plans to lower the cash rate by 100 basis points to 4.25 per cent. \\
\hline February 2009 & The Australian Government announced an AUD 42 billion stimulus package titled the Nation Building and Jobs Plan. \\
\hline February 2009 & The RBA announced plans to lower the cash rate by 100 basis points to 3.25 per cent. \\
\hline April 2009 & The RBA announced plans to lower the cash rate by 25 basis points to 3 per cent \\
\hline May 2009 - August 2010 & No further boost strategy was announced by the Government. \\
\hline $\begin{array}{l}\text { October } 2009 \text { - August } \\
2010\end{array}$ & The RBA announced plans to raise the cash rate from 3 per cent to 4.5 per cent \\
\hline
\end{tabular}

Table 5 Australia's response to the late 2000s global financial crisis 
the pre-crisis period with no effects of the global financial crisis, and the change in construction demand is assumed to follow the trend of economic growth in the post-crisis era.

The estimates of the VEC models indicate that over $81 \%$ of variation in construction demand can be explained by the selected economic indicators. The lagged construction demand, the growth of population and the interest rate have significant roles in explaining the level of demand in the construction industry. Residential, non-residential and overall construction demands in Australian construction industries were affected significantly by both the recent global financial crisis and seasonality. Construction demand in the non-residential industry was affected more significantly than the residential industry by the crisis, shown by comparing the results of the net effect both in Scenarios $A$ and $B$. It is also found that the actual residential construction demand is in line with the movements of the residential construction demand with intervention analysis, when compared with actual non-residential construction demand and its estimated value. This suggests that the residential construction industry was more reactive and was able to recover faster when experiencing a global crisis in comparison with the non-residential industry. The impact from the lagged effect of the crisis is worse than the onset of the crisis. Despite the effectiveness of the economy boost strategies issued by the Australian government, construction demand experienced a significant decline after the government removed the stimulation plan. According to the results of the intervention analysis, government policy makers should note that lagged negative effects on the non-residential construction demand became worse from 2009Q4 to 2010Q2, and a further boost strategy, such as increasing investments on construction, needs to be implemented to allow the Australian construction industry to recover from the late 2000 s financial crisis.

This study focused on the impact of the recent global financial crisis and seasonality. Other global events and factors affecting the construction industry, such as the 1997 Asian Financial Crisis, the 2000 Sydney Olympic Games and the September 11 attacks, have not been considered in the scope of this study. . In particular, an abnormal variation of construction demand was observed in Australia during 2001 and 2002. This major depression was largely due to a change in Australian government policy regarding the new taxation law which came into effect in 2001. However, the VEC model with intervention indicators used in this study served as an experiment for an advanced econometrical method, which can be used to analyse the effect of special events and factors on construction and other industries.

\section{References}

ABS 2012, Australian economic indicators. Canberra, Australia Bureau of Statistics

Akintoye, A., Bowen, P. \& Hardcastle, C. 1998, 'Macro-economic leading indicators of construction contract prices', Construction Management and Economics, 16 (2), 159-175

Akintoye, A. \& Skitmore, M. 1994, 'Models of UK private sector quarterly construction demand', Construction Management and Economics, 12 (1), 3-13

Ball, M., Farshchi, M. \& Grilli, M. 2000, 'Competition and the persistence of profits in the UK construction industry', Construction Management and Economics, 18 (7), 733-745

Berkmen, P., Gelos, R. G., Rennhack, R. \& Walsh, J. 2009, The global financial crisis: Explaining cross-country differences in the output impact, International Monetary Fund Working Papers WP/09/280, available at http://www.imf.org/external/pubs/cat/longres.aspx?sk=23438.0 access on 15/08/2013.

Blankenburg, S. \& Palma, J. G. 2009, 'Introduction: the global financial crisis', Cambridge Journal of Economics, 33 (4), 531-538.

Bonham, C., Gangnes, B. \& Zhou, T. 2009, 'Modeling tourism: A fully identified VECM approach', International Journal of Forecasting, 25 (3), 531-549. 
Box, G. E. P. \& Tiao, G. C. 1975, 'Intervention analysis with applications to economic and environmental problems', Journal of the American Statistical Association, 70 (349), 70-79.

Dicky, D.A. \& Fuller, W.A. 1979, 'Distribution of the estimators for autoregressive time series with a unit root', Journal of the American Statistical Association, 74 (336a), 427-431

Engle, R. F. \& Granger, C. W. J. 1991, Long-run economic relationships: readings in cointegration, Oxford University Press, New York.

Fan, R. Y. C., Ng, S. T. \& Wong, J. M. W. 2010, 'Reliability of the Box-Jenkins model for forecasting construction demand covering times of economic austerity', Construction Management and Economics, 28 (3), 241-254.

Hua, G. B. 1998, 'Forecasting residential construction demand in Singapore: a comparative study of the accuracy of time series, regression and artificial neural network techniques', Engineering, Construction and Architectural Management, 5 (3), 261-275.

Hua, G. B. 2005, 'The dynamic effects of the Asian financial crisis on construction demand and tender price levels in Singapore', Building and Environment, 40 (2), 267-276.

Hui, E. C. M. \& Yue, S. 2006, 'Housing price bubbles in Hong Kong, Beijing and Shanghai: a comparetive study', The Journal of Real Estate Finance and Economics, 33 (4), 299-327.

Jiang, H. \& Liu, C. 2011, 'Forecasting construction demand: A vector error correction model with dummy variables', Construction Management and Economics, 22 (9), 969-979.

Johansen, S. \& Juselius, K. 1990, 'Maximum likelihood estimation and inference on cointegration -- with applications to the demand for money', Oxford Bulletin of Economics and Statistics, 52 (2), 169-210.

Li, Y. \& Liu, C. 2012, 'Labour productivity measurement with variable returns to scale in Australia's construction industry', Architectural Science Review, 55 (2), 110-118.

Liu, C., Ma, L., Luo, Z. \& Picken, D. 2009, 'An interdependence analysis of Australian house prices using variance decomposition', International Journal of Housing Markets and Analysis, 2 (3), 218-232.

Ma, L \& Liu, C. 2013, 'Spatio-temporal analysis of house price convergence based on a demographical distance', International Journla of Strategic Property managemnt, 17(3), 263277.

Meikle, J. 2001, 'A review of recent trends in house construction and land prices in Great Britain', Construction Management and Economics, 19 (3), 259-265.

Murphy, L. 2011, 'The global financial crisis and the Australian and New Zealand housing markets', Journal of Housing and the Built Environment, 26 (3), 335-351.

Nayyar, D. 2011, 'The financial crisis, the great recession and the developing world', Global Policy, 2 (1), 20-32.

Ofori, G. 1990, The construction industry: aspects of its economics and management, Singapore University Press, Singapore.

Phillips, P. C. B. \& Perron, P. 1988, 'Testing for a unit root in time series regression', Biometrika, 75 (2), 335-346.

Ramey, V. 1993, How important is the credit channel in the transmission of monetary policy?, Carnegie-Rochester Conference Series on Public Policy, North-Holland.

Song, Y. \& Liu, C. 2006, 'The Australian construction linkages in the 1990s', Architectural Science Review, 49 (4), 408-417.

Tang, J. C. S., Karasudhi, P. \& Tachopiyagoon, P. 1990, 'Thai construction industry: demand and projection', Construction Management and Economics, 8 (3), 249-257.

Yap, G. \& Allen, D. 2011, 'Investigating other leading indicators influencing Australian domestic tourism demand', Mathematics and Computers in Simulation, 81 (7), 1365-1374. 